\title{
Reinhold Niebuhr y el realismo agustiniano en Relaciones Internacionales: Hallazgos arqueológicos del giro postsecular en la disciplina
}

\author{
ÁNGEla IrANZo DosDAD*
}

\section{RESUMEN}

La influencia de las ideas religiosas en la Teoría de Relaciones Internacionales ha sido un tema poco explorado por la deriva secularista y cientificista de la disciplina. Sin embargo, bajo el giro postsecular, varios teóricos han empezado a problematizar los efectos político-normativos del paradigma de la secularización y a releer críticamente los orígenes y desarrollos de la teoría de Relaciones Internacionales. En este marco, el artículo estudia la influencia de san Agustín en los orígenes de la escuela realista. Analiza cuándo y cómo la obra agustiniana llegó al realismo clásico, a través de una relectura de los conceptos de naturaleza humana, historia y orden, formulados por el Obispo de Hipona en clave dialéctica. Asimismo, el artículo demuestra la influencia de estos conceptos agustinianos en la formulación del realismo esperanzado de Reinhold Niebuhr, reconocido como el padre de los realistas en Relaciones Internacionales.

\section{Palabras Clave}

Teoría de Relaciones Internacionales; post-secular; realismo;Agustín de Hipona; Reinhold Niebuhr. \section{tio}

*Ángela

IRANZO DOSDAD, Investigadora asociada del Departamento de Relaciones Internacionales y Humanidades de la Universidad de Deusto Email: angela.iranzo@ deusto.es.

\section{Recibido:}

22/10/2018

Aceptado:

05/02/2019

\section{Title}

Reinhold Niebuhr and Augustinian realism in International Relations: Archeological findings from the postsecular turn in the discipline

\begin{abstract}
The influence of religious ideas on the International Relations Theory has not been explored due to the secularist and scientific trends of the discipline. However, under the post-secular turn, some theorists have begun to revisiting the modern secularist paradigm as well as reconsidering the origin and development of International Relations Theory. Within this framework, the article explains the influence of Saint Augustine's thought on the origins of the Realist school of International Relations. It studies how and when the Augustinian ideas arrived in classical realism through a new reading of his concepts of human nature, history and order. Likewise, the article analyses the influence of Augustinian ideas on the "hopeful realism" developed by Reinhold Niebuhr, who is recognized as the father of realists in International Relations.
\end{abstract}

\section{KEYWORDS}

International Relations Theory; post-secularism; realism;Augustine of Hippo; Reinhold Niebuhr.

\section{DOI:}

https://doi.org// 0.15366/relacionesinternacionales2019.40.002

\section{Formato de citación recomendado:}

IRANZO DOSDAD, Ángela,"Reinhold Niebuhr y el realismo agustiniano en Relaciones Internacionales. Hallazgos arqueológicos del giro postsecular en la disciplina”, en Relaciones Internacionales, n 40, 2019, pp. 5 I - 68. 
Para Francisco Javier Peñas, un pensador de la política internacional tan profundo como sincero; un realista agónico, tan ateo como crítico con los delirios fáusticos del secularismo liberal.

\section{$\mathrm{I}$}

\section{ntroducción}

La tendencia dominante entre los teóricos de Relaciones Internacionales (RRII) ha sido acudir al pensamiento de Tucídides, Maquiavelo, Hobbes y, en ocasiones, a MaxWeber como las fuentes conformadoras de la escuela realista. Sin embargo, a finales de los años ochenta y principios de los noventa, varios teóricos iniciaron un giro heterodoxo para la disciplina de RRII, al explorar la influencia de Agustín de Hipona como otra posible fuente de realismo político'.

El máximo exponente de esta influencia fue el político, académico y teólogo protestante estadounidense Reinhold Niebuhr, a quien George Kennan definió como "el padre de todos nosotros [los realistas]"'. Las ideas de Niebuhr influyeron en reconocidos realistas como Edward H. Carr y Hans J. Morgenthau, y lo hizo a través de un realismo cristiano (esperanzado) que bebía de la obra agustiniana ${ }^{3}$. El teólogo norteamericano encontró en La Ciudad de Dios herramientas conceptuales válidas para responder a inquietudes que la crisis del periodo de entreguerras planteaba con urgencia. Morgenthau diría en 1962 que Niebuhr era "the greatest living political philosopher in America"4; y Greg Rusell defendía que la influencia de Niebuhr sobre Morgenthau era la repuesta a la paradójica forma en que el pensador judío alemán explicaba la relación entre moralidad y política de poder en Política entre las naciones ( 1948) —unas veces, al estilo Maquiavelo y otras apelando a principios de moralidad trascendente ${ }^{5}$ -

Pero la influencia de las ideas religiosas en la escuela realista y, en general, en las RRII como cuerpo científico, ha sido normalmente entendida como un hallazgo arqueológico raro en el mejor de los casos, una curiosidad- en las profundidades de la historia del pensamiento político moderno ${ }^{6}$. La razón está en el especial arraigo del paradigma de la secularización en la disciplina, marcadamente eurocéntrica y fuertemente seducida por el racionalismo positivista

BROWN, Chris, International Relations Theory. New Normative Approaches, Columbia University Press, Nueva York, I992; LORIAUX, Michael, "The Realists and Saint Augustine: Scepticism, Psychology and Moral Action in International Relations Thought" en International Studies Quarterly, vol. 36, n 4, 1992, pp. 40 I-420; EPP, Roger, The “Augustinian Moment” in International Politics. Niebuhr, Butterfield, Wight and the Reclaiming of a Tradition, Department of International Politics, University College of Wales, Aberystwyth, I99I; y Power Politics and the Civitas Terrena: the Augustinian Sources of Anglo-American Theory in International Relations, Queen's University, Kingston, Ontario, I990; MURRAY, Alastair J., Reconstructing Realism. Between Power Politics and Cosmopolitan Ethics, Keele University Press, Edimburgo, I 997; SMITH, Michael J., Realist Thought from Weber to Kissinger, Louisiana State University Press, Londres, 1986; ROSENTHAL, Joe H., Righteous Realists-Political Realism, Responsible Power and American Culture in the Nuclear Age, Louisiana State University Press, Baton Rouge, I99I.

2 SMITH, Michael J., Realist Thought..., op. cit.

3 RICE, Daniel F., Reinhold Niebuhr and his circle of influence, Cambridge University Press, Cambridge, 20I2; MOLLOV, Benjamin M., Power and Transcendence. Hans J. Morgenthau and the Jewish Experience, Lexington Books, Oxford, 2002; MURRAY,Alastair J., "The moral politics of Hans Morgenthau” en The Review of Politics, vol. 58, n I, I996, pp. 8I-I07.

4 MORGENTHAU, Hans J., "The influence of Reinhold Niebuhr in American Political Life and thought” en LANDON, Harold R. (ed.), Reinhold Niebuhr:A prophetic voice in our times, Seabury Press, Greenwich, 1962, p. 109.

5 RUSELL, Greg, Hans J. Morgenthau and the Ethics of American Statecraft, Louisiana University Press, Londres, 1990, pp. 74-75.

6 THOMAS, Scott. M.,"Talking religious and cultural pluralism seriously:The global resurgence of religion and the transformation of international society" en PETITO, Fabio y HATZOPOULOS, Pavlos (eds.), Religion in International Relations. The return from exile, Palgrave Macmillan, Nueva York, 2003; PHILPOTT, Daniel, “The Challenge of September II to Secularism IR" en World Politics, n. 55, 2002 , pp. 66-95. 
apenas iniciada su andadura como disciplina de las ciencias sociales. La religión ha sido, por tanto, uno de los silencios de las RRII7. Sólo recientemente, la disciplina ha emprendido un giro crítico, postsecular, para comprender el rol de las identidades y prácticas religiosas en la política global contemporánea y, a su vez, develar los efectos, en clave de poder discursivo, derivados del arraigo del paradigma moderno de la secularización en la Teoría de RRII.

Este artículo se enmarca en el espíritu del giro postsecular, con la intención de contribuir a mostrar que el realismo en RRII no ha estado tan secularizado como los manuales y materiales docentes sobre la disciplina - especialmente, en lengua castellana - acostumbran a afirmar. El artículo, por tanto, contesta la narrativa secularista9 que, de forma dominante, ha reconstruido selectivamente los orígenes y desarrollos del realismo político internacional. La influencia de las ideas religiosas, en general, y del cristianismo, en particular, puede identificarse en diferentes desarrollos teóricos de RRII ${ }^{10}$. Sin embargo, el artículo se centra en la teoría realista por dos motivos: primero, la tendencia a interpretar su propuesta política como amoral y, segundo, la asunción sobre su carácter moderno y efectivamente secularizado. Tampoco se trata de abogar por una teología política internacional" . Más bien, la intención es sacar a la luz la pluralidad de voces que han articulado el realismo clásico en RRII, sin jerarquías epistémicas y prejuicios moderno-ilustrados ${ }^{12}$.

El escrito se estructura en tres partes. La primera sitúa en el periodo de entreguerras el resurgimiento del agustinismo político en los círculos académicos europeos y estadounidenses. La segunda explica los principales aportes de san Agustín al realismo clásico en relación a tres conceptos: naturaleza humana, historia y moralidad política. La tercera, explica cómo Reinhold Niebuhr se basó en la obra agustiniana para formular su realismo esperanzado, ni idealista ni cínico, como guía normativa en la arena internacional. Finalmente, unas conclusiones cierran el artículo mostrando, a su vez, la reciente recuperación de Niebuhr por algunos teóricos como para orientar la acción de gobiernos como la Administración de Obama o como inspiración para atemperar las tendencias a la radicalización de posiciones políticas.

\section{La recuperación de Agustín de Hipona durante la crisis de entreguerras (1919- 1939)}

A medida que avanzaban los años treinta, las posibilidades prácticas del internacionalismo liberal wilsoniano se mostraban cada vez más remotas e ingenuas. La llegada de la Segunda Guerra Mundial era inminente y estaban siendo fuertemente cuestionados los pilares teóricos que habían

\footnotetext{
PETITO, Fabio y HAZTOPOULOS, Pavlos (eds.), Religion in International..., op. cit.

8 MAVELLI, Luca y PETITTO, Fabio (eds.), Towards a postsecular international politics, Palgrave Macmillan, Nueva York, 20I4; CALHOUN, Craig, JUERGENSMEYER, Mark y VAN ANTWERPEN, Jonathan (eds.), Rethinking Secularism, Oxford University Press, Nueva York, 20I I.

9 De acuerdo con Shakmann que se inspira en la revisión crítica del concepto "secular" realizada por Talal Asad, el "secularismo" es una categoría política que, a modo de ideología, prescribe las formas de relación aceptables para una democracia liberal, entre religión, política y sociedad.Véase: SHAKMAN, Elizabeth, The Politics of Secularism in International Relations, Princeton University Press, Princeton y Oxford, 2008

10 SANDAL, Nukhet A. y FOX, Jonathan, Religion in International Relations Theory, Routledge, Londres y Nueva York, 2013.

" Véase: KUBÁLKOVÁ,Vendulka, “Towards an International Political Theology” en PETITO, Fabio y HATZOPOULOS, Pavlos (eds.), Religion in International Relations, Palgrave Macmillan, Nueva York, 2014.

12 Para los teóricos del giro post-secular, habitamos en un mundo post-metafísico en el que el rechazo a la búsqueda de verdades universales exige reconocer e integrar en el debate público las diferentes formas de inteligibilidad sobre el mundo, sea científica, religiosa, basada en saberes étnicos u otros. No existe jerarquía epistémica entre ellos.
} 
apuntalado, hasta entonces, la concepción idealista del orden internacional ${ }^{13}$.

Cada vez eran más quienes, fruto de la decepción, la angustia, la sensatez o la valentía de intentar cambiar el desalentador curso de los hechos, reconocían que la confianza en la sola razón, en la historia como progreso y en la institucionalidad internacional, no bastaban para alcanzar un cierto orden de seguridad y paz internacional. Edward H. Carr decía que esta crisis no podía explicarse como una época de maldad excepcional, como sugirió Toynbee, o de estupidez excepcional, como dijo Zimmern, ni tampoco como un periodo transitorio de retroceso, como resolvió Lauterpatch. Para Carr la explicación era otra:"puede ser no que los hombres fracasaran estúpida o malvadamente al aplicar principios justos, sino que los propios principios fueran falsos o inaplicables"'/4.

Ante la urgencia de hallar alternativas, el cristianismo bíblico se convirtió en una opción importante en los países de habla inglesa y, especialmente, la recuperación del pensamiento agustiniano. En 1939, cuando Hitler invadió Polonia tras la anexión de Checoslovaquia, Niebuhr pronunció en Edimburgo las Gifford Lectures of Theology con el propósito presentar una línea de acción política intermedia, que criticaba por igual el sentimentalismo idealista (liberal) y el cinismo o resignación (conservador). Su propuesta era releer en clave contemporánea la obra de san Agustín, La Ciudad de Dios.

Para intelectuales de la época, particularmente en los campos de la historia, la filosofía política y la teología, la obra de san Agustín aportaba claves para explicar el fracaso del proyecto liberal tras la Primera Guerra Mundial, al tiempo que ofrecía material para formular una nueva idea de orden internacional que fuese, ante todo, verdaderamente realista.

Desde este círculo de pensadores cristianos, al que también pertenecían los teólogos suizos Karl Barth y Emil Brunner, arrancaron sus reflexiones sobre política internacional los historiadores europeos Herbert Butterfield (metodista) y Martin Wight (anglicano), así como el teólogo y teórico político estadounidense Reinhold Niebuhr (protestantismo bíblico). Desde un sustrato común realista, Butterfield y Wight pusieron las bases en Europa de la Escuela Inglesa de Relaciones Internacionales ${ }^{15} \mathrm{y}$, aunque menos reconocido que los anteriores, Niebuhr pavimentó el terreno para el surgimiento de la escuela realista en Estados Unidos. En los tres autores se aprecian ideas derivadas de su cristianismo compartido. En los tres sus desarrollos teóricos están a medio camino entre el idealismo y el realismo más escéptico; se interesan por la historia, defienden la ambigüedad de la naturaleza humana, y se preocupan particularmente por la justicia en política internacional. Les diferenciaba, sin embargo, su diferente sensibilidad hacia la legalidad en el orden internacional; un elemento ausente en la obra de Niebuhr. Los tres creían que su fe tenía algo que decir a y sobre el poder ${ }^{16}$, y defendieron la tradición agustiniana hasta que el giro

13 Según Raymond Aron, la escuela realista de Relaciones Internacionales nació en el periodo de entreguerras como el "thinking against" el optimismo ingenuo del internacionalismo liberal.

14 CARR, Edward H., La crisis de los veinte años (19/9-1939), Libros de La Catarata, Madrid, 2004, p. 80.

15 Sobre la influencia del cristianismo en los orígenes de la Escuela Inglesa, véase: JONES, Charles, "Christian Realism and the Foundation of the English School” en International Relations, vol. 17, n. 3, 2003, pp. 37I-387; THOMAS, Scott M., "Faith, History and Martin Wight:The role of religion in the historical sociology of the English School of International Relations" en International Affairs, vol. 77, $n^{\circ}$. 4, 200I; $y$ sobre las diferencias y similitudes entre Niebuhr y Butterfield, veáse: MCINTIRE, C.T. (eds.), God, History and Historians, Oxford University Press, Nueva York, 1977.

16 PATTERSON, Eric (ed.), The Christian Realists: Reassessing the contributions of Reinhold Niebuhr and his Contemporaries, University Press of 
behaviourista despreció todo vestigio de filosofía, historia y normatividad en la disciplina ${ }^{17}$.

Incluso liberales como Alfred E. Zimmern, primero en ocupar la Cátedra Woodrow Wilson de RRII en la Universidad de Aberystwyth y activo defensor de la Sociedad de Naciones, encontraron en Agustín de Hipona un punto de referencia para repensar la concepción idealista de orden internacional. Tomando la reflexión del Obispo de Hipona sobre el orden, concluía que éste debía concebirse, principalmente, como una aspiración ${ }^{18}$.

Pensadores de la política internacional acogieron, en los años treinta y cuarenta, las ideas agustinianas. Según Marrou, podría explicarlo el hecho de que "[san Agustín] nos instruye mediante su ejemplo sobre el arte de vivir en una época de catástrofe"|'. Varios intelectuales establecieron una analogía entre la época de crisis civilizatoria que vivió san Agustín con la invasión de Roma en el año 410 y la crisis de conciencia occidental que motivó y resultó en la Segunda Guerra Mundial, el totalitarismo y el Holocausto nazi. En el ensayo titulado “Augustine's Political Realism" (I953), Niebuhr defendía que La Ciudad de Dios ofrecía pautas explicativas adecuadas sobre las fricciones, tensiones y conflictos comunes a la condición humana en distintos contextos históricos ${ }^{20}$. Ideas contenidas en esta obra podían viajar al siglo $X X$ y reformulase en la urgente búsqueda de respuestas políticas para la coyuntura mundial de entonces.

La Ciudad de Dios se escribió como respuesta a la crisis espiritual que provocó en los cristianos el saqueo de la ciudad de Roma por las tropas visigodas de Alarico. En aquel entonces, en el Imperio Romano occidental, la causa del mundo se asimilaba a la causa de Roma, concebida como la "ciudad eterna". Según la concepción grecorromana de la historia, Roma era la cuarta monarquía imperial, sucesora de Babilonia, Persia y Grecia; cada una de las cuales había caído de forma inevitable sucumbiendo ante la próxima gran potencia. No obstante, para algunos, Roma era también la quinta monarquía; cerraría el ciclo histórico-temporal de la Humanidad y no caería, sino que viviría eternamente.

Sin embargo, la población pagana y muchos cristianos consideraron que la causa de la tragedia sobre Roma era la nueva teopolítica cristiana -la conversión al cristianismo de Constantino y la proclamación del Imperio romano cristiano- y la eliminación de los antiguos cultos del politeísmo. De este modo, la doctrina de salvación cristiana, ejemplificada en la alianza entre política y religión, estaba en crisis. Ante esta situación, san Agustín escribió La Ciudad de Dios y contribuyó a salvar la legitimidad de la Iglesia cristiana en el mundo mediante una idea: la dialéctica entre las dos ciudades, la civitas dei y la civitas terrena.

La recuperación del pensamiento agustiniano entre los años treinta y sesenta del siglo $X X$ aportó a la Filosofía de la Historia, la Teoría Política y a las RRII una alternativa intermedia, como

17 CATELLIN, Luca Gino, “The Realist of Distances: Reinhold Niebuhr and the 'Great Debates' in IR" en Open Journal of Political Science, vol. 4, n I, 2014, p. 35.

${ }^{18}$ En una ponencia ("The Ethical Presuppositions of World Order”) pronunciada en 1937, Zimmern dijo que quienes habían contribuido a propagar la religión del internacionalismo eran culpables de confundir el pensamiento y errar en la práctica. Acudió al pensamiento agustiniano para explorar la posibilidad de una noción de orden internacional más realista.

19 MARROU, Henri-Irénée, St. Augustine and his influence thought Ages, Harper Toechbooks, Nueva York, 1957 , p. 7.

20 NIEBUHR, Reinhold, “Augustine’s political realism” en Christian Realism and Political Problem, Charles Scribner's Sons, Nueva York, 1953.
} 
se explicará a continuación, entre los principios morales absolutos y la ausencia de ellos en la vida social y política. La Ciudad de Dios exponía con claridad la cuestión del dilema moral, no en términos de tensión disyuntiva entre absolutos, sino de dialéctica entre valores contrarios.

\section{Aportaciones del pensamiento agustiniano al realismo político}

Según Roger Epp, "san Agustín bien podría ser una fuente sorprendente de teoría de Relaciones Internacionales"21. El obispo de Hipona vivió en una época en la que no existía conciencia de un saber internacional como tal. Sin embargo, formuló ideas que, de una forma u otra, están presentes en los desarrollos filosóficos de realistas como Niebuhr, Carr, Morgenthau y Kennan.

A continuación, se explican los aportes del realismo agustiniano (esperanzado) a la tradición realista de RRII. El estudio se realiza sobre tres ejes conceptuales presentes en las tradiciones de pensamiento político internacional: la naturaleza humana, el sentido de la historia y la articulación entre moralidad y política ${ }^{22}$.

\section{I. La naturaleza humana: dialéctica entre libertad y finitud}

El vértice del pensamiento agustiniano está en su concepción bíblica de la naturaleza humana. Según esta, una dialéctica entre libertad y finitud define al ser humano como "hijo de Dios" y "criatura" al mismo tiempo. No obstante, para san Agustín, la nota esencial del ser humano es la libertad, pues fue creado por Dios como un ser libre. Es más, es precisamente esta libertad la que le lleva a infringir el mal, haciendo de él un ser finito y cognitivamente limitado.

De aquí deriva una concepción de la naturaleza humana en la que el mal es parte de ella ${ }^{23}$. El mal no es algo creado por Dios en la naturaleza, sino que su origen está en la voluntad libre del ser humano. Por lo tanto, el origen del mal no está en el cuerpo, sino en el espíritu, en el ánimo humano ${ }^{24}$.Así, como defenderán los teóricos del realismo clásico en RRII, la concepción agustiniana afirma que de lo bueno (la voluntad humana libre) puede nacer lo malo (el pecado); en otras palabras, el bien no necesariamente se traduce en buenos resultados, como había demostrado el fracaso del proyecto liberal idealista.

Pero si bien la causa del mal reside en el espíritu humano y el ser humano se convierte en finito con la Caída, la doctrina agustiniana no reconoce en estas circunstancias fuerzas suficientes para anular, por completo, la creatividad humana. El pecado original no implica la pérdida de libertad y de capacidad racional en sí, sino que las limita; hace del individuo un ser no-autosuficiente, incapacitado para conocer el sentido último de la vida que, desde entonces, permanece para él “escondido". Hallarlo dependerá de la gracia de Dios, afirma, que les ilumina en este conocimiento a través de la fe. Así, el agustinismo subraya los límites del conocimiento racional, pero no por ello desalienta a los humanos a alimentarlo durante su experiencia mundana. Diría: "hay que comprender para creer" (intellige ut credas); creer no es, por tanto, repetir las fórmulas de una profesión de fe" 25 .

\footnotetext{
21 EPP, Roger, “The ‘Agustinian'...”, op. cit., p. 3.

22 WIGHT, Martin, International Theory. The Three Traditions, Leicester UP, Londres, 1991.

${ }^{23}$ HIPONA, Agustín, La Ciudad de Dios, Biblioteca Homo Legens, Madrid, 2006, p. 436.

24 lbídem, p. 535.

${ }^{25}$ MARROU, Henri-Irénée, San Agustín y el agustinismo, Aguilar, Madrid, 1960, p. 83.
} 
La fe alumbra un conocimiento que no consiste en dar a conocer a los humanos el significado último de la vida (logos), sino que les ayuda a aprender a ignorar lo que es preciso saber que no se puede saber en este mundo. Esta manera de formular la libertad (limitada) del individuo en el mundo es una de las notas más destacadas de la doctrina agustiniana entre los pensadores realistas cristianos de RRII. A diferencia del pesimismo luterano que erradica toda confianza en la capacidad humana y de corrientes como el misticismo que impulsa la huida espiritual de este mundo como forma de afrontar la ardua realidad, el agustinismo enfatiza una lectura humilde de la libertad del ser humano.

Pese a su permanente dialéctica con la finitud, originada en el pecado original, defendía que la libertad no deja de ser una fuerza creativa en el ser humano y en las sociedades. Esta concepción de la naturaleza humana explica el deseo de pensadores realistas cristianos como Buttelfield, Wight y Niebuhr de reconciliar idealismo y realismo porque, más que doctrinas contrapuestas, son dos estados diferentes del ánimo humano, intrínsecamente relacionados. Así, siguiendo la dialéctica agustiniana, Niebuhr reivindicaba la necesidad de síntesis entre idealismo y cinismo porque todo ser humano es, a su vez, "hijo de la luz" e "hijo de las sombras"26.

\subsection{La historia: dialéctica entre tiempo y eternidad}

Existe cierto consenso sobre el rechazo de san Agustín a la idea pagana de los ciclos cósmicos y la introducción, en su lugar, de una concepción de la historia lineal, finita y cargada de sentido que contiene una noción rectilínea del tiempo ${ }^{27}$.

La categoría "tiempo" fue central en las explicaciones de san Agustín sobre la creación del mundo y la historia de la humanidad. A diferencia de la filosofía clásica, defendía que dios no sólo creó el orden y la disposición, sino también la sustancia. De modo que el tiempo se creó cuando el mundo fue creado. Dios es un creador externo, atemporal, pero Agustín de Hipona formuló una teoría del tiempo según la cual este no es ni pasado ni futuro, porque sólo el presente es realmente. De modo que todo tiempo es presente (ahora) en sentido propio, porque el pasado es una evocación presente del "ya no" y el futuro es una evocación presente del "aún no".

Las tres dimensiones del tiempo se anudan en el presente de la existencia particular del sujeto - su animus - El agustinismo reconoce tres tiempos: un presente de cosas pasadas (memoria), un presente de cosas presentes (visión) y un presente de cosas futuras que identifica con la expectación (expectatio futurorum) ${ }^{28}$. De este modo, introduce la dimensión (subjetiva) del tiempo futuro, una expectatio proyectada en una línea temporal. Es, por tanto, una concepción del tiempo finita, con un principio, un medio y un fin, que rompe con la eterna concepción circular pagana para alcanzar la meta final de salvación y descanso eterno.

La concepción cíclica del tiempo de los clásicos era problemática para san Agustín porque no ayuda a liberar la existencia humana de las miserias. Por ello, calificó la doctrina pagana de desesperanza porque toma los tiempos pasados y los venideros como fases iguales de un ciclo

\footnotetext{
${ }^{26}$ NIEBUHR, Reinhold, The children of light and the children of darkness: A vindication of democracy and a critique of its traditional defense, Charles Scribner's Sons, Nueva York, 1944.

27 MARRAMAO, Giacomo, Poder y secularización, Ediciones Península, Barcelona, 1989.

${ }^{28}$ KOSELLECK, Reinhard, Los estratos del tiempo. Estudios sobre la historia, Paidós, Barcelona, 200 I, p. II 7.
} 
eterno, sin principio ni fin, lo cual por definición elimina la esperanza y la fe en el futuro. Esta incesante repetición excluye la posibilidad de pensar en la felicidad verdadera y en las acciones necesarias a emprender en la vida terrenal para llegar a ella. Por lo tanto, como subrayaría Löwith, la idea agustiniana de tiempo futuro es un antecedente del concepto de progreso como filosofía moderna de la historia ${ }^{29}$; una concepción claramente contenida en las formulaciones liberales y marxistas de RRII, pero también presente en el realismo político cristiano bajo una versión atemperada como muestran las obras de Niebuhr o Wight.

El futuro se convierte en el telos de la historia, pero la verdadera historia para san Agustín es la dialéctica entre las dos ciudades, la terrena y la celestial, en una peregrinación (peregrinatio) que conducirá al fin último: la salvación mediante la plena realización de la ciudad de Dios. Cabe no olvidar que la ciudad del hombre (civitas terrena) y la ciudad de Dios (civitas dei) son una ficción imaginaria con la que el Obispo de Hipona trata de representar dos formas de vida diferentes, pero no por ello opuestas. Al contrario, las dos ciudades forman parte de un todo (ordo) que hace regir entre ellas una relación dialéctica de complementariedad.

Así, si la concepción agustiniana de la historia consiste en la dialéctica entre las dos ciudades, esta también implica la dialéctica entre dos dimensiones del tiempo y dos nociones de historia. Por un lado, desde su creación por dios, la ciudad terrena encarna un proceso temporal —de ahí su denominación de saeculum que significaba siglo o era-y la historia en ella no puede entenderse más allá de un proceso natural histórico en el tiempo. Por esa razón, el fin de la historia en la ciudad terrena ha de entenderse en términos de "finis"; esto es, fin orgánico de la vida. Por otro lado, la ciudad de dios es eterna, encarna el no-tiempo, y la historia en relación a ella es una meta-historia. En esta dimensión, el fin de la historia alude no a un final orgánico ("finis"), sino al telos o sentido último de la existencia.

Así, lo eterno, la perfección y el amor divino (caritas) se insertan y forman parte del proceso temporal, imperfecto y manchado del deseo egoísta (cupiditas) de la ciudad del hombre. Las dos historias, mundana y cósmica, están intrínsecamente entrelazadas. Por ello, el agustinismo no desmerecía el tiempo presente, la vida en el saeculum, instando a los seres humanos a la realización de un orden (paz y justicia) posible; esto es, a la medida humana.

\subsection{El orden: dialéctica entre cupiditas y caritas}

Agustín de Hipona propuso una idea de orden finalista, en sintonía con su teleología de la historia. Como escribió Hedley Bull, inspirándose en la obra agustiniana, hay dos posibles interpretaciones de orden: una pauta o regularidad en las relaciones entre los individuos, y una pauta que conduce a un resultado, a un fin concreto $^{30}$. Esta última está cargada de normatividad y es el tratamiento que dio san Agustín al concepto de orden.

El orden es una idea central del agustinismo político y un concepto normativamente más elevado que la justicia cuando se trata de la vida social y política mundana; lo cual es una característica del realismo clásico en RRII. La dialéctica (histórica) entre la ciudad del hombre y la ciudad de dios, lleva a asociar lo político a la primera y lo espiritual a la segunda. Sin embargo, lo

29 LÖWITH, Karl, El sentido de la historia, Aguilar, Madrid, I968, pp. I4-I5.

30 BULL, Hedley, La sociedad anárquica. Un estudio sobre el orden en la política mundial, Libros de la Catarata, Madrid, 2005. 
político no está meramente encorsetado en el saeculum, sino que es parte de un todo cósmico formado por una jerarquía de fines que ascienden gradualmente y cada uno de los cuales sirve a un orden y a una autoridad apropiada (ordo $)^{3 !}$.

Está claro que, al final del proceso histórico temporal, las dos ciudades se sumergirán en un ordo total, la ciudad de dios. Pero, hasta ese momento, la vida en el saeculum también asume el telos del ordo dando un significado particular a las estructuras sociales y políticas de la ciudad terrenal. En otras palabras, si bien el orden perfecto sólo es realizable en la ciudad de dios, el orden político no está condenado a la injusticia.

Lejos de condenar la ciudad del hombre al caos y a la injusticia, el Obispo de Hipona insiste en que cada parte del "todo" debe entenderse bajo sus propios parámetros y, por ello, la ciudad terrenal posee su propio sentido de orden y justicia. Por esta razón, es deber de los cristianos darse a la creatividad social y a la acción moral frente a los problemas y tragedias del mundo. El realismo agustiniano está, por tanto, lejos de la contemplación pasiva, del quietismo o la inquietud fáustica del hombre moderno.

"La esperanza escatológica no sofoca todo el ardor de la actividad temporal de los cristianos, y La Ciudad de Dios no se desentiende de fomentar la pax terrena que es el doble ideal de cristianos y no cristianos" 32 .

Sin embargo, la paz en la ciudad terrena siempre es una especie de armisticio. Sólo cabe alcanzar en ella un orden precario, frágil. La injusticia es consustancial a toda sociedad desde el momento de la Caída, y lleva a la imposición de la coerción política que no es propia del orden natural de las cosas, sino del orden temporal del saeculum. Así, la paz terrenal sólo puede resultar del orden político, entendido como un sistema de relaciones que reconocen y se ajustan a la finitud de la naturaleza humana.

Asimismo, si el orden es la condición previa a la paz y esta busca alcanzar cierto grado de justicia, para el pensador cristiano el patrón de justicia es la ley de amor. Para él, el amor es el principio que sustenta el ordo (ordo est amoris). El potencial normativo de una comunidad humana no está en la búsqueda de la justicia — sobre todo, entendida en términos legales—, sino del amor. Según Niebuhr, el amor para san Agustín es un principio que permite la realización de la justicia en las infinitas formas que presentan las configuraciones históricas y humanas; es un principio normativo atemporal ${ }^{33}$.

Hannah Arendt estudió el concepto de amor de san Agustín y se inspiró en sus conceptos de caritas e initium para formular su concepción de la política como acción ${ }^{34}$. En el pensador cristiano, el amor tampoco escapa al juego dialéctico.

\footnotetext{
${ }^{31}$ LAUBACH, Donna, “Aspectos del pensamiento político de San Agustín en el contexto de la crisis del Imperio”. Ponencia seminario Evangélico Unido de Teología, Madrid, 2006, p. 5.

32 HIPONA, Agustín, La Ciudad..., op. cit., Pp. XLVIII-XLIX.

33 NIEBUHR, Reinhold, Christian Realism and Political Problems, Charles Scribner's Sons, Nueva York, I 953, p. I34.

34 ARENDT, Hannah, El concepto de amor en san Agustín, Encuentro, Madrid, 2009.Véase también: FERNÁNDEZ, Daniel, “El concepto de amor en Hannah Arendt" en Foro Interno. Anuario de Teoría Política, vol. I6, 2016, pp. I0I-I 22.
} 
Aunque san Agustín diferenció tres tipos de amor (appetitus, cupiditas y caritas) ${ }^{35}$, dio especial relevancia a los dos últimos. El amor puro, desinteresado, es propio de la ciudad de Dios, mientras que en la ciudad terrenal habita el amor expiatorio. Este está basado en la culpa que comparte toda la humidad como descendientes de Adán y Eva, y que es entendida como el fundamento del amor al prójimo. Ese amor expiatorio, cupiditas, motiva a los cristianos a participar del caritas.

La Ciudad de Dios ofrece, por lo tanto, una posible articulación teórica entre la política de poder y una moralidad trascendente que obliga a los cristianos a asumir de forma comprometida esta tensión en su paso por la vida mundana. Nunca será posible fundar una "verdadera" ciudad o república con un "verdadero" sentido de la justicia en el saeculum ${ }^{36}$. No obstante, como defiende el realismo esperanzado, es posible y deseable trabajar para alcanzar un orden social y político que vislumbre los principios de justicia de la Ciudad de Dios.

\section{Reinhold Niebuhr: el puente entre Agustín de Hipona y el realismo en Relaciones Internacionales}

\section{I.El optimismo pesimista}

La producción intelectual de Niebuhr estuvo siempre marcada por la tensión entre el ser y el deber ser, leída en clave agustiniana. Por ello, Michael Smith lo define como "el puente de unión entre los siglos que separan a san Agustín y a los realistas modernos" ${ }^{\text {"37. }}$

Experimentó giros muy significativos a lo largo de su vida. De la teología cristiana liberal de sus años universitarios en Yale, pasó al marxismo tras su actividad pastoral con los trabajadores de Detroit.Y, no encontrando aquí una respuesta satisfactoria, se interesó por el realismo agustiniano durante su etapa en la Union Theological Seminary en Nueva York, donde llegó en I928. Pero todavía experimentaría un nuevo giro hacia el liberalismo, ya no marcado por la ilusión optimista wilsoniana sino aplacado por el pragmatismo que caracterizaba la política exterior de presidentes como Franklin D. Roosevelt ${ }^{38}$.

Sin embargo, a pesar de estos cambios de dirección, hay una constante en su pensamiento político que ayuda a comprenderlos:la permanente evaluación del liberalismo. Partía de la necesidad de comprender la ineludible tensión entre lo ideal y lo real, pero proponía una lectura realista de la política internacional que no abandonase el optimismo. Defendía una ética realista pero vitalista que no renunciase a la capacidad creativa de los seres humanos, en tanto hijos de Dios dotados de libertad. Lo explicaba con claridad en un fragmento de "Augustine's political realism" (1953):

"Los «realistas» modernos conocen el poder del interés egoísta de los pueblos como lo hizo san Agustín; pero no comprenden su ceguera. Los pragmáticos

\footnotetext{
35 El appetitus responde a un deseo ardiente de aquello que no se tiene; el cupiditas es un amor errado por las condiciones de vida terrenales; y el caritas es el amor justo en busca de lo eterno.

${ }^{36}$ Con esta idea, san Agustín había encontrado una explicación a la caída de Roma que calmase la ansiedad de los cristianos y paganos de su época. Al demostrar que Roma no era la "ciudad eterna" porque solo la ciudad de dios permanece eternamente, acababa con la idolatría al Imperio Romano cristiano como la mejor mancomunidad posible. De este modo, defenderá que nadie debe lealtad incondicional a una sociedad terrenal, una idea que adelanta principios del liberalismo.

37 SMITH, Michael. J., Realist Thought..., op. cit., p. 23.

38 STONE, Ronald H., Reinhold Niebuhr: Prophet to Politicians, University of Press America, Washington, I98I.
} 
modernos entienden la irrelevancia de las normas específicas y fijas; pero no comprenden que el amor debe ocupar el último lugar ante los inadecuado de estas. Los cristianos liberales modernos saben que el amor es la ley principal del ser humano, pero caen en el sentimentalismo porque se equivocan al infravalorar el poder y la persistencia del egoísmo"39.

Definir al pensador norteamericano como un optimista pesimista, y no a la inversa, busca enfatizar que la nota final y central de su ética política es el optimismo, pues posee una confianza última en la trascendencia de la existencia y en el significado de la vida y de la historia. Pero, al mismo tiempo, posee un pesimismo provisional en el sentido de escepticismo. Es escéptico ante la inteligibilidad última del ser humano y posibilidad de alcanzar la perfección social que ensalzaba el liberalismo idealista ${ }^{40}$. Sin embargo, este pesimismo provisional no le hace renunciar a la persecución de la justicia, pero tampoco a ignorar el sentido trágico de la vida. Niebuhr reivindicaba un deber ético ante las dinámicas de poder del mundo internacional, llamando a una ética responsable no perfeccionista.

El teórico estadounidense formuló su ética política a partir de las doctrinas del hombre y de la historia que dan cuerpo a los dos volúmenes de su obra The Nature and Destiny of Man. Uno de los vértices de su ética política está en la ambivalencia que, para el cristianismo, caracteriza la naturaleza humana. Como se ha explicado en el epígrafe anterior, entiende al ser humano como "criatura" e "imagen de Dios" al mismo tiempo y, por tanto, una dialéctica entre libertad y finitud caracteriza su naturaleza. Decía que el hombre es libre de trascender su inmediatez, aunque finalmente no puede escapar de su finitud ${ }^{41}$. La libertad es por tanto la nota que hace único al ser humano, si bien la tragedia acompaña toda su experiencia vital. Niebuhr lamentaba que el pesimismo de la tragedia griega, próximo a la interpretación bíblica de la vida, fuese uno de los elementos de la Grecia clásica que el pensamiento moderno no incorporó entre sus fundamentos ${ }^{42}$.

Por otra parte, también encontró en el pensamiento agustiniano uno de los vértices de su ética política por ofrecer una concepción de la historia más dinámica que la clásica y menos optimista que las interpretaciones modernas, cimentadas en la muchas veces peligrosa idea de progreso. Consideraba que este esquema moderno de "salvación" mundana era otro esfuerzo en vano para evadir la incómoda verdad de que somos los seres humanos los autores de muchos de los males que sufrimos ${ }^{43}$. Asimismo, la tragedia fue un rasgo también habitual en su noción de historia, aunque transitaría hacia la idea de ironía ${ }^{44}$.

"El drama de la historia humana está, en su totalidad, bajo el escrutinio del juez

\footnotetext{
39 NIEBUHR, Reinhold, “Augustine’s political realism” en Christian Realism and Political Problem, Charles Scrubner’s Sons, Nueva York, I953, p. 146.

40 NIEBUHR, Reinhold, “Optimism, Pessimism and Religious Faith” en MCAFFE, Robert, The Essential Reinhold Niebuhr,Yale University Press, New Haven y Londres, 1986, p. 5.

4 STONE, Ronald H., Reinhold Niebuhr..., op. cit., p. 96.

42 NIEBUHR, Reinhold, The Nature and Destiny of Man. Human Nature, Nisbet \& Co. LTD, Londres, I94I, p. 12.

43 NIEBUHR, Reinhold, Faith and History. A Comparison of Christian and Modern Views of History, Nisbet \& Co. LTD, Londres, 1949 , p. 36.

${ }^{44}$ En la obra Man's Nature and His Communities (1965), propone un liberalismo pragmático que le lleva a revisar los principios y doctrinas centrales de su filosofía política; entre ellos, su doctrina de la historia. Su primer tratamiento de la historia como ironía se encuentra en The Irony of American History, Charles Scribner's Sons, Nueva York, 1952.
} 
divino, quien se ríe de las pretensiones humanas, pero sin mostrarse contrario a sus aspiraciones (...) La interpretación bíblica de la situación humana es irónica, más que trágica o patética, por su exclusiva formulación del problema de la libertad humana" 45 .

Como puede observarse, sus doctrinas del hombre y de la historia están fuertemente influenciadas por la obra agustiniana, resultando en una visión realista del mundo que no es ni cínico ni resignado frente a las vicisitudes de la vida. Lo que Niebuhr criticaba era el optimismo superficial e ingenuo. El problema teológico sobre el mal viaja hasta sus reflexiones políticas, poniendo en primer plano la pregunta sobre cómo conjugar la "inevitabilidad del mal" y la "libertad del ser humano"; y, más allá, cómo conjugar la "inevitabilidad del mal" y la responsabilidad del individuo y de las naciones, como explica el próximo epígrafe.

Si bien el pecado original impide al ser humano conocer las leyes de dios, insiste en la importancia de la libertad de la voluntad cuando la responsabilidad humana se ve amenazada ${ }^{46}$. Es el momento de desplegar la creatividad humana. Así, la principal preocupación de Niebuhr es evitar concepciones del mal que apunten a la depravación absoluta, destruyendo la idea de responsabilidad y viciando el significado del pecado ${ }^{47}$. Rechazaba por ello el pesimismo de Lutero y Hobbes, que puede llevar a una promoción sin restricciones del poder estatal. No entender que los peligros de la anarquía internacional son tan preocupantes como los peligros de la tiraría del gobernante, significaba no ser lo suficientemente realista ${ }^{48}$.

Por ejemplo, en el contexto de la Guerra Fría, Niebuhr criticaba el sentido contraproducente de la antítesis entre idealistas y realistas (en Estados Unidos) como respuesta a la amenaza de la Unión Soviética. Los idealistas apostaban por la creación de un gobierno mundial que garantizase la paz y disipase la inevitabilidad de la guerra. Esta posición era desacertada por ingenua, pero cabía no descartarla totalmente ante la propuesta de los realistas que defendían emprender una guerra preventiva, aceptando la inevitabilidad de la guerra y la imposibilidad de llegar a un acuerdo con el poder soviético. En definitiva, enfatizar los factores de poder e interés egoísta no es, para Niebuhr, contrario a la búsqueda de la justicia posible.

\subsection{La moralidad individual y la moralidad de las naciones}

En la obra El hombre moral y la sociedad inmoral (1932), Niebuhr ofrece una reinterpretación del estándar de dualidad moral; difundido entre los realistas, principalmente, por la obra de Maquiavelo. Sin embargo, preocupado por la crisis política de entreguerras, su objetivo era responder la asunción idealista sobre la equivalencia o armonía entre la moralidad individual y la que se puede esperar de los grupos sociales y, especialmente, de las naciones ${ }^{49}$.

Rechaza esta posibilidad y explica la distinción entre la moralidad de los individuos y

\footnotetext{
45 Ibídem, p. 155.

${ }^{46}$ NIEBUHR, Reinhold, The Nature and Destine of Man. Human Nature, Nisbet \& Co. LTD, Londres, I94I, p. 258.

47 Ibídem, p. 263.

${ }^{48}$ NIEBUHR, Reinhold, “Augustine's Political...”, op. cit., p. 127.

49 LITTLE, David, “The Recovery of Liberalism: Moral Man and Immoral Society Sixty Years Later” en Ethics \& International Affairs, vol. 7, I993, p. 179.
} 
la de las naciones recurriendo a la tensión entre lo ideal y real. En concreto, esta tensión se manifiesta en la dialéctica entre el amor y la justicia. El amor (caritas) es el principio que debe guiar el comportamiento de las personas, pero en las naciones solo cabe una moralidad basada en la justicia que se traduce en un orden relativo, precario y contingente. Esta tensión entre la moralidad del amor y la moralidad de la justicia se ha descrito, en ocasiones, como la laguna entre moralidad y política en la obra niebuhriana.

Sin embargo, abordó de forma expresa la articulación entre moralidad y política de poder en su explicación sobre la "moralidad de las naciones" en El hombre moral y la sociedad inmoral. Reconoce en la nación moderna al grupo de cohesión social más fuerte, de autoridad central más indiscutida y de asociación más claramente definida.A continuación, aborda el interrogante sobre la actitud moral de las naciones que, aunque reconoce no necesariamente asociadas a un estado, suelen tener a su disposición —al menos, en este capítulo de la historia - un aparato estatal, poseedor de los medios necesarios para inspirar temor y respeto.

Para el realista cristiano, son dos las notas que definen el comportamiento moral de las naciones: el egoísmo y la hipocresía. Sobre el primero, considera iluso contemplar la posibilidad de erradicar la nota egoísta del comportamiento humano, social y político. Rechaza la confianza del liberalismo en la razón, de la teología cristiana más entusiasta en la inspiración religiosa y del marxismo en la lucha de clases para, por el contrario, afirmar el deber ético de contener el egoísmo —más que acabar con él-.

Como realista político, Niebuhr reconoce el egoísmo de las naciones y la persecución del interés nacional, pero los entiende desde un enfoque que supera la habitual concepción moderna de la política de poder como moralmente aséptica ${ }^{50}$. Comprender este egoísmo implica, en primer lugar, aceptar que es parte de la naturaleza humana. No obstante, Niebuhr llama también la atención sobre el contacto precario e indirecto entre las comunidades nacionales que forman un cierto tipo de comunidad internacional. "Esta es la triste historia de la ignorancia social de las naciones" 51 .

Percibir las necesidades ajenas y comprender los intereses en conflicto entre naciones son condiciones para la justicia internacional que exigen una proximidad al otro. Pero en la práctica de la política internacional de mediados del siglo $X X$, esto no era lo habitual. El desconocimiento social entre los pueblos refuerza la idea del egoísmo de las naciones y contribuye a legitimar la persecución del interés nacional como una de las máximas ineludibles del comportamiento estatal.

Aquí, según Niebuhr, la aproximación agustiniana permite corregir el reduccionismo de la visión que los realistas modernos tienen sobre el interés nacional; pues, este no es la última palabra de la política internacional ${ }^{52}$.

\footnotetext{
50 Niebuhr diferencia tres acepciones de poder: como sinónimo de energía que expresa la vitalidad humana y es moralmente neutro; como sinónimo de fuerza que expresa el impulso de dominación humano como consecuencia de su egoísmo e inseguridad, que es negativo moralmente; y como principio de organización y cohesión social, necesario para evitar el caos, cuya connotación moral es positiva. Véase: STONE, Ronald H., Reinhold Niebuhr..., op. cit., p. I 77.

51 NIEBUHR, Reinhold, El hombre moral y la sociedad inmoral, Ediciones Siglo Veinte, Buenos Aires, I966, p. 91.

52 CASTELLINI, Luca G., The Realist of Distances..., op. cit., p. 33.
} 
"Es tan grande la ignorancia social de los pueblos que, lejos de hacer justicia a un enemigo o a un vecino, no son siquiera capaces de contemplar con sabiduría sus propios intereses. Dado que sus intereses finales están siempre mejor protegidos al aplicar siquiera una pequeña dosis de justicia a sus vecinos, el deseo de conseguir una ventaja egoísta inmediata hace peligrar sus intereses finales" ${ }^{\prime 3}$.

Una política exterior sabia depende en gran medida del reconocimiento de los intereses de otras naciones.

“(...) la más elevada moralidad posible para las naciones parece ser, no el sacrificio de sus intereses, sino un interés propio prudente que sepa hallar el punto de concurrencia entre sus intereses nacionales y aquéllos más universales" 54 .

Este intento de armonizar intereses no debe confundirse, sin embargo, con la doctrina liberal de la armonía de intereses o la promoción de un gobierno mundial. Para Niebuhr, éste último es inviable por, al menos, tres realidades: la inexistencia de un verdadero tejido social bajo la llamada "comunidad internacional", la existencia de un poder desigual entre estados y la dominación de los fuertes sobre los débiles ${ }^{55}$.

Asimismo, Niebuhr acude también al patriotismo para explicar el comportamiento egoísta de las nacionales. En primer lugar, identifica aquí una paradoja ética: el altruismo individual de unos (los ciudadanos dispuestos a dar su vida por la patria) se convierte en una forma de egoísmo social y nacional (lo nuestro, primero y ante todo). Por lo tanto, el patriotismo alimenta la lealtad nacional que, en demasiadas ocasiones, acaba destruyendo la actitud crítica del individuo hacia la nación y sus empresas, enalteciendo el carácter sagrado de la causa nacional y evidenciando el egoísmo de las naciones.

El resultado, es una devoción que da base al poder estatal y justifica la libertad de hacer uso de él sin inhibiciones morales ${ }^{56}$. En la medida en que el patriota cae en un comportamiento antisocial, justificando en términos de interés nacional su mediocridad moral, su actitud es un ejemplo de egoísmo social que se aleja de cualquier posibilidad de justicia internacional al perder la empatía con el otro.

Por otra parte, junto al egoísmo, la hipocresía es otra de las características morales más significativas de una nación. Para Niebuhr, la clave aquí no consiste en juzgar el comportamiento de las naciones por desenmascarar sus verdaderas motivaciones (materiales y egoístas). Más bien subraya que si bien el autoengaño puede empezar siendo una estrategia política, casi siempre es una necesidad humana y social. Por lo tanto, dirá que más vale comprender la hipocresía que censurarla porque proviene de la naturaleza paradójica del ser humano.

\footnotetext{
${ }^{53}$ NIEBUHR, Reinhold, El hombre moral..., op. cit., p. 90.

${ }^{54}$ DAVIS, Harry y GOOD Robert C. (eds.), Reinhold Niebuhr on Politics, Charles Scribner's Sons, Nueva York, 1960, p. 328. Citado en STONE, Ronald H, Reinhold Niebuhr..., op. cit., p. 199.

${ }^{55}$ NIEBUHR, Reinhold, “The Illusion of World Government” en Christian Realism and..., op. cit.

${ }^{56}$ NIEBUHR, R., El hombre moral..., op. cit., p. 95.
} 
Explicados el egoísmo y la hipocresía como rasgos recurrentes en el comportamiento moral de las naciones, Niebuhr defiende que es en las situaciones de conflicto cuando la nación cobra conciencia de sí misma; cuando se encuentra en yuxtaposición con otra comunidad nacional y busca los rasgos que la caracterizan. En estas coyunturas, la autocrítica es necesaria y Niebuhr asocia dicha capacidad a la autotrascendencia. En otras palabras, encuentra la fuente del orden político internacional en una moralidad trascendente, inspirada por los valores de la fe cristiana que encuentran su síntesis en la ley de amor (al prójimo) o caritas. De este modo, los imperativos morales trascendentes deben estar presentes en la acción política, si bien la realidad y una política responsable no permite más que moderarlos en la práctica — guiados por la humildad cristiana—.

En definitiva, el estadista, consciente de su responsabilidad moral, debe buscar de forma realista la moralidad internacional a partir de una definición humilde del interés nacional, capaz de conjugarse con los intereses de otras naciones. De este modo encontraba Niebuhr un posible antídoto contra el fanatismo de los fines absolutos que mostraba el auge de los fascismos antes y durante la Segunda Guerra Mundial.

\section{Conclusiones}

Las ideas religiosas, particularmente el cristianismo, influyeron en los desarrollos teóricos que fundaron la disciplina de RRII. Sin embargo, dicha influencia ha sido tradicionalmente silenciada en una disciplina que se ha construido a sí misma bajo la asunción de ser moderna y, por ello, estar efectivamente secularizada.

Las ideas religiosas has estado, por el contrario, presentes en la Teoría de RRII y, como muestra este artículo,una de las modalidades que acoge la escuela realista es el realismo esperanzado, inspirado en san Agustín. Por lo tanto, lejos de ser amoral, el realismo clásico ofrece diversas formas de anudar moralidad y política de poder. Lo habitual en la disciplina es acudir al realismo cínico que pone la moralidad al servicio de los intereses del príncipe (Maquiavelo), o a la raison d'ètat que hace de la supervivencia del estado el bien supremo que justifica toda acción necesaria para su realización (Hobbes). Sin embargo, el artículo demuestra la existencia de otra posible forma resolver el dilema moral en política internacional. Esta tiene su fuente en el pensamiento agustiniano y su máximo exponente en el teólogo, académico y político estadounidense, Reinhold Niebuhr.

Aunque poco conocido entre los teóricos de RRII, Niebuhr ejerció una notable influencia en Carr, Morgenthau y Kennan poniendo las bases de la escuela realista. Encontró en La Ciudad de Dios de san Agustín herramientas conceptuales para comprender la crisis política de su época y orientar la política exterior estadounidense durante la Segunda Guerra Mundial y la Guerra Fría.Atraído por el sentido dialéctico que san Agustín dio a los conceptos de naturaleza humana, historia y orden, Niebuhr abogó por la necesidad de una síntesis entre idealismo y realismo, defendiendo un realismo esperanzado de base cristiana. De ahí la calificación de su ética política como una muestra de optimismo pesimista y no a la inversa; pues, aunque el mal es parte del ser humano y de las sociedades en que habita, destacaba la libertad como el principal atributo concedido por Dios a los seres humanos.

Egoísmo e hipocresía son los rasgos característicos del comportamiento de las naciones, 
pero esto no anula el deber de responsabilidad y creatividad humana, social y política. Por ello, el teólogo protestante animaba al gobierno estadounidense a hallar en los principios de la fe cristiana un referente de moralidad internacional, basado en la idea de amor al prójimo (caritas). Esta era una forma de equilibrar intereses nacionales opuestos, tratando de alcanzar un orden que, aunque precario y frágil, aspirase a la justicia posible. Defendía el amor como un principio normativo más efectivo que la legalidad para el orden internacional.

El pensamiento político de Niebuhr no fue uniforme a lo largo de su vida, y por ello ha recibido diversos calificativos como realista esperanzado, profético, liberal atemperado o pragmático, entre otros. Pero, es justamente en su posición intermedia, dialéctica, ecléctica y distanciada de los absolutos, donde algunos autores como Tjalve ${ }^{57}$, Holder y Josephson ${ }^{58} \circ$ Marques $^{59}$ han hallado recientemente una fuente de inspiración para orientar una política internacional realmente realista; esto es, basada en la aceptación de la ambivalencia del ánimo humano y las tensiones de la política.

Aunque algunos autores llevan años estudiando en solitario la influencia de la religión en la teoría política internacional, el giro postsecular advierte sobre la necesidad de releer críticamente los desarrollos teóricos de RRIl; de problematizar la dicotomía "religioso" vs. "secular" y asociaciones derivadas de ella (como tradición vs. modernidad, mito vs. realidad, fe vs. razón, o autoritarismo vs. democracia). Como muestra el artículo, la voz de Niebuhr impactó en los orígenes de la disciplina con una propuesta de base cristiana que, aunque no exenta de críticas, no por ello era menos moderna, racional, secular y ética que aquellas definidas sin alusión a vocabulario religioso.

\section{Bibliografía}

ALHOUN, Craig, JUERGENSMEYER, Mark y VAN ANTWERPEN, Jonathan (eds.), Rethinking Secularism, Oxford University Press, Nueva York, 20I I.

ARENDT, Hannah, El concepto de amor en san Agustín, Encuentro, Madrid, 2009.

BAKER, Ernst, "St. Augustine's Theory of Society" en BAKER, Ernest, Essays on Government, Clarendon Press, Oxford, 195I, pp. 234-269.

BROWN, Chris, International Relations Theory. New Normative Approaches, Columbia University Press, Nueva York, 1992. BULL, Hedley, La sociedad anárquica. Un estudio sobre el orden en la política mundial, Libros de la Catarata, Madrid, 2005. CARR, Edward H., La crisis de los veinte años (1919-1939), Libros de La Catarata, Madrid, 2004.

CATELLIN, Luca Gino, "The Realist of Distances: Reinhold Niebuhr and the 'Great Debates' in IR" en Open Journal of Political Science, vol. 4, $\mathrm{n}^{\circ}$ I, 20I4, pp. 3 I-38.

DAVIS, Harry y GOOD Robert C. (eds.), Reinhold Niebuhr on Politics, Charles Scribner's Sons, Nueva York, 1960.

DEANE, Herbert A., The Political and Social Ideas of St. Augustine, Columbia University Press, Nueva York, 1963.

EPP, Roger, Power Politics and the Civitas Terrena: the Augustinian Sources of Anglo-American Theory in International Relations, Queen's University, Kingston, Ontario, 1990.

EPP, Roger, The "Augustinian Moment" in International Politics. Niebuhr, Butterfield, Wight and the Reclaiming of a Tradition, Department of International Politics, University College of Wales, Aberystwyth, 1991.

FERNÁNDEZ LÓPEZ, Daniel, "El concepto de amor en Hannah Arendt" en Foro Interno. Anuario de Teoría Política, vol. 16, 2016, pp. 101-122.

57 TJALVE, Vibeke S., American Jeremiahs: Reinhold Niebuhr, Hans J. Morgenthau and the Realist Recovery of a Republican Peace, Departamento de Ciencia Política, Universidad de Copenhague, 2005.

58 HOLDER, R. War y JOSEPHSON, Peter B., The Irony of Barack Obama: Barack Obama, Reinhold Niebuhr and the Problem of Christian Statecraft, Ashgate, Farnham, Surrey, 2012.

59 MARQUES, Guilherme, Reinhold Niebuhr and IR: Realism beyond Thomas Hobbes, Routledge, Londres, 2017. 
FORTINE, Ernest L., “Augustine’s City of God and the Modern Historical Consciousness” en The Review of Politics, vol. 4I, n 3, 1979, pp. 323-343.

HIPONA, Agustín, La Ciudad de Dios, Biblioteca Homo Legens, Madrid, 2006.

HOLDER, R.War y JOSEPHSON, Peter B., The Irony of Barack Obama: Barack Obama, Reinhold Niebuhr and the Problem of Christian Statecraft, Ashgate, Farnham, Surrey, 2012.

JONES, Charles, “Christian Realism and the Foundation of the English School” en International Relations, vol. I7, $\mathrm{n}^{\circ} .3$, 2003, pp. 37I-387.

KENNAN, George F., “Morality and Foreign Policy” en Foreign Affairs, invierno, 1985/86, pp. 205-2I8.

KOSELLECK, Reinhard, Los estratos del tiempo. Estudios sobre la historia, Paidós, Barcelona, 200I.

LANDON, Harold R. (ed.), Reinhold Niebuhr:A prophetic voice in our times, Seabury Press, Greenwich, 1962.

LAUBACH, Donna, "Aspectos del pensamiento político de San Agustín en el contexto de la crisis del Imperio". Ponencia seminario Evangélico Unido de Teología, Madrid, 2006.

LITTLE, David, “The Recovery of Liberalism: Moral Man and Immoral Society Sixty Years Later” en Ethics \& International Affairs, vol. 7, I993, pp. I7I-20I.

LORIAUX, Michael, "The Realists and Saint Augustine: Scepticism, Psychology and Moral Action in International Relations Thought” en International Studies Quarterly, vol. 36, n 4, 1992, pp. 40 I-420.

LÖWITH, Karl, El sentido de la historia, Aguilar, Madrid, 1968.

MARKUS, RobertA., Saeculum: History and Society in the Theology of St.Augustine, Cambridge University Press, Cambridge, 1970.

MARQUES, Guilherme, Reinhold Niebuhr and IR: Realism beyond Thomas Hobbes, Routledge, Londres, 2017.

MARRAMAO, Giacomo, Poder y secularización, Ediciones Península, Barcelona, 1989.

MARROU, Henri-Irénée, St. Augustine and his influence thought Ages, Harper Toechbooks, Nueva York, 1957.

MARROU, Henri-Irénée, San Agustín y el agustinismo, Aguilar, Madrid, 1960.

MATTHEWS, Gareth B., Agustín, Herder, Barcelona, 2006.

MAVELLI, Luca y PETITTO, Fabio (eds.), Towards a postsecular international politics, Palgrave Macmillan, Nueva York, 2014.

MCAFFE, Robert, The Essential Reinhold Niebuhr, Yale University Press, New Haven y Londres, 1986.

MCINTIRE, C.T. (ed.), God, History and Historians, Oxford University Press, Nueva York, 1977.

MOLLOV, Benjamin M., Power and Transcendence. Hans J. Morgenthau and the Jewish Experience, Lexington Books, Oxford, 2002.

MURRAY, Alastair J., "The moral politics of Hans Morgenthau” en The Review of Politics, vol. 58, n I, I 996, pp. 8I- 107.

MURRAY, Alastair J., Reconstructing Realism. Between Power Politics and Cosmopolitan Ethics, Keele University Press, Edimburgo, 1997.

NIEBUHR, Reinhold, The Nature and Destiny of Man. Human Nature, Nisbet \& Co. LTD, Londres, I94I.

NIEBUHR, Reinhold, The children of light and the children of darkness: A vindication of democracy and a critique of its traditional defense, Charles Scribner's Sons, Nueva York, 1944

NIEBUHR, Reinhold, Faith and History.A Comparison of Christian and Modern Views of History, Nisbet \& Co. LTD, Londres, 1949.

NIEBUHR, Reinhold, Christian Realism and Political Problems, Charles Scribner's Sons, Nueva York, 1953.

NIEBUHR, Reinhold, El hombre moral y la sociedad inmoral, Ediciones Siglo Veinte, Buenos Aires, 1966.

PATTERSON, Eric (ed.), The Christian Realists: Reassessing the contributions of Reinhold Niebuhr and his Contemporaries, University Press of America, Lanham, 2003.

PETITO, Fabio y HATZOPOULOS, Pavlos (eds.), Religion in International Relations. The return from exile, Palgrave Macmillan, Nueva York, 2003.

PETITO, Fabio y HATZOPOULOS, Pavlos (eds.), Religion in International Relations, Palgrave Macmillan, Nueva York, 2014

PHILPOTT, Daniel, “The Challenge of September II to Secularism IR” en World Politics, n. 55, 2002, pp. 66-95.

RICE, Daniel F., Reinhold Niebuhr and his circle of influence, Cambridge University Press, Cambridge, 2012.

RICH, Paul, "Reinhold Niebuhr and the Ethics of Realism in International Relations" en History of Political Thought, vol. 13, n², 1992, pp. 28I-298.

ROSENTHAL, Joe H., Righteous Realists-Political Realism, Responsible Power and American Culture in the Nuclear Age, Louisiana State University Press, Baton Rouge, I991.

RUSELL, Greg, Hans J. Morgenthau and the Ethics of American Statecraft, Louisiana University Press, Londres, 1990.

SANDAL, Nukhet A. y FOX, Jonathan, Religion in International Relations Theory, Routledge, Londres y Nueva York, 2013.

SHAKMAN, Elizabeth, The Politics of Secularism in International Relations, Princeton University Press, Princeton y Oxford, 2008.

SMITH, Michael J., Realist Thought from Weber to Kissinger, Louisiana State University Press, Londres, 1986.

STONE, Ronald H., Reinhold Niebuhr: Prophet to Politicians, University of Press America, Washington, I98I.

THOMAS, Scott M., "Faith, History and Martin Wight: The role of religion in the historical sociology of the English School of International Relations" en International Affairs, vol. 77, n 4, 200 I, pp. 905-929.

TJALVE, Vibeke S., American Jeremiahs: Reinhold Niebuhr, Hans J. Morgenthau and the Realist Recovery of a Republican Peace, Departamento de Ciencia Política, Universidad de Copenhague, 2005.

TUCKER, Robert W., "Professor Morgenthau's Theory of Political 'Realism”" en The American Political Science Review, 
vol. 46, $n^{\circ}$ I, 1952, pp. 214-24.

WIGHT, Martin, International Theory. The Three Traditions, Leicester UP, Londres, I99I. 


\section{RELACIONES INTERNACIONALES}

Revista académica cuatrimestral de publicación electrónica Grupo de Estudios de Relaciones Internacionales (GERI)

Universidad Autónoma de Madrid, España

https://revistas.uam.es/relacionesinternacionales

ISSN 1699 - 3950

f facebook.com/RelacionesInternacionales

3. twitter.com/RRInternacional 